\title{
The importance of energy resources for Azerbaijan's international competitiveness
}

\author{
Krzysztof Falkowski \\ World Economy Research Institute, Warsaw School of Economics \\ Poland \\ k.falkow@sgh.waw.pl
}

Abstract. The aim of this paper is to present a detailed analysis of the international competitiveness of Azerbaijani economy and, based on it, to determine the importance of energy resources and their derivatives in shaping the competitive profile of its economy in international trade during 2000-2015. In order to assess the country's international trade competitiveness, two indicators have been applied, i.e., Balassa's Revealed Comparative Advantages (RCA) index and the Lafay Index (LFI) of international trade specialization. The analysis conducted clearly shows that Azerbaijan's overall international trade competitiveness is low, especially with respect to high and medium-high technology goods, while the only comparative advantages of its economy include exports of goods from the medium-low technology category, in which energy resources and their derivatives are classified. This proves the absolute key importance of these resources in the competitive profile of Azerbaijani economy, and to a large extent determines its resources-based character. This makes its further development strongly dependent on international markets for energy resources, thus increasing its susceptibility to external shocks.

Keywords: international competitiveness, international trade, energy resources, Azerbaijan.

JEL Classification: F14, O11, Q33, Q37

\section{INTRODUCTION}

Since the beginning of the 21 st century, Azerbaijan has recorded very high economic growth, making it not only the economic leader in the Caucasus region, but also ranking it among the fastest growing socalled post-Soviet countries. Suffice it to say that in the years 2000-2014 Azerbaijan's GDP grew more than 14 times, from USD 5.27 billion in 2000 to USD 75.24 billion. In 2015, mainly as a result of falling oil prices at the world markets, Azerbaijan's GDP shrank to USD 53.07 billion. The consequence of such strong economic growth was also strong economic and social development, which was exemplified by an increase in GDP per capita PPP (purchasing power parity) from USD 3,534 in 2000 to USD 17,782 in 
2015 (that is, a 5-fold increase), as a result of which the country is now classified as upper-middle-income (World Bank Database, 2018).

In the context of the above, an important and at the same time very interesting research issue is answering the question of how and to what extent the rapidly developing economy of Azerbaijan is competitive on the international arena (or more precisely, in contemporary international trade), and above all, what importance in this competitiveness play the country's energy resources and their derivatives.

In order to answer the above questions, two indicators were used to assess the country's competitiveness in international trade, i.e., Balassa's Revealed Comparative Advantages (RCA) index and the Lafay Index (LFI) of International Trade Specialization.

From the detailed analysis conducted, it is clear that Azerbaijani economy's international trade competitiveness is low, especially in the categories of high- and medium-high technology goods. A direct excuse for this state of affairs is the complete lack of comparative advantages in these two categories, which, from the viewpoint of the specificity of today's world economy and the constantly growing demand for goods with high and medium-high technological advancement, should be regarded as a clearly negative phenomenon. On the other hand, importance of the possessed and exploited energy resources and their derivatives for the competitiveness of Azerbaijani economy in international trade is absolutely crucial.

In view of the above, when formulating general recommendations for a competition policy (as part of the overall economic policy) for Azerbaijani authorities, it seems absolutely necessary to implement a consistent, pragmatically formulated strategy to increase the diversification of the existing structure of the country's economy, aimed at the development and modernisation of the non-oil sector, which is an absolute prerequisite for improving the country's international competitiveness. Necessary financial resources for these activities should come, first of all, from the revenues of energy resources' and their derivatives' export, which in practice would mean actual discounting the comparative advantages in international trade possessed by Azerbaijan in relation to these goods. It also seems imperative to create a transparent legal framework (e.g., to eliminate legal inconsistencies, protect property rights and, above all, increase the effectiveness of the fight against corruption), necessary to raise investment attractiveness for foreign (but also domestic) capital and to implement innovative projects, including research and development projects, in Azerbaijan. All of the above will eventually have positive effects on the competitiveness of Azerbaijan's economy.

Taking into account the Azerbaijani authorities' existing awareness of the threats resulting from its economy's excessive dependence on the natural resources possessed and the resulting deindustrialisation of Azerbaijan's economy, one can hope for a gradual improvement of both the competitiveness as well as the structure of the country's GDP. Despite some formal steps already taken by the authorities of Azerbaijan towards these changes, the tangible effects expected in terms of the country's competitive profile are not yet visible, as evidenced by the research results presented in this article.

\section{LITERATURE REVIEW AND DERIVATION OF THESES}

The issue of the international competitiveness of the Azerbaijani economy is not discussed as often in economic literature as the issue of the country's dynamic resources-driven development. Publications about Azerbaijan very often draw attention to the country's specificity in terms of the dominant role of the broadly understood oil sector in generating its GDP, while at the same time clearly having a relatively underdeveloped non-oil sector, which is characterised by low competitiveness (Ibragimova \& Isayev, 2017; Zeynalov, 2016; Bahmani-Oskooee \& Jamilov, 2014). In this context, Azerbaijan is seen as a classic example of an economy affected by the so-called Dutch disease (Mukhtarov, 2018; Hasanov, 2013). 
Moreover, as Bayramov et al. (2014) points out, currently the share of oil sector in the Azerbaijani industry amounts to as much as $80 \%$ as compared to only $4.8 \%$ in 1990 . Its role is therefore enormous from the point of view of the functioning of the whole economy, however, it is an extremely precarious situation for the future development of Azerbaijan, having a significant negative impact on its competitiveness, as it has effectively transformed the country into a raw materials exporter only. From this point of view, it seems absolutely necessary to make attempts and efforts to increase production and export of more finished goods at much higher profit margins, instead of raw materials. A change from being an exporter of raw oil to an exporter of processed oil products would not only improve Azerbaijan's competitiveness in international trade, but would also be much more beneficial to its economy, for the following reasons. First, it is resource-efficient so the current oil reserves will be depleted at a much lower rate. Secondly, it is four times more profitable in terms of margin. And thirdly, it will create more jobs than in the current oil industry.

Aliyev (2014), on the other hand, stresses another important issue for the international trade competitiveness of the country's economy, that is the need to continuously improve its low level of innovation. However, this will not be possible without significant investment into the Azerbaijani economy from FDIs (Pashayev, 2013). Moreover, Pashayev (2013, p. 30) explicitly states that to become sustainable the Azerbaijani economy needs to get more competitive and a shift towards technologically advanced and innovation friendly production is necessary with balanced approach to manufacturing, services and agriculture.

Not only economists but also politicians responsible for economic policy in Azerbaijan have for some time become increasingly aware that a gradual but consistent change of its structure is necessary for the competitiveness of the Azerbaijani economy and its future stable development. And this is happening gradually. Over the past few years, thanks to the growing funds flowing from the export of energy resources to the state budget, we can observe that the country's authorities have been taking measures aimed at diversifying the existing structure of the Azerbaijani economy in order to foster the development of the non-oil sector to raise its competitiveness and export possibilities, making it independent from the oil price or the oil revenues (Azerbaijan 2020: Look into the Future, 2013). As a result of these activities and in connection with the observed decline in the prices of energy resources on world markets, since 2011 an increase in the share of the non-oil sector in the Azerbaijani GDP has been observed, as Musayev points out (2016).

According to the synthetic overview of the economic literature on the economy of Azerbaijan conducted above, there is a specific gap in the scope of detailed research on its competitive profile of the Azerbaijani economy, including in particular its international trade competitiveness, with particular emphasis on the competitiveness of its energy resources and their derivatives in the international arena. Some point out that, on the one hand, the Azerbaijani economy is highly dependent on energy resources while its competitiveness in international trade is low, on the other, but there is a lack of quantitative research that empirically confirms these facts. This article is intended to fill this gap and that is its novelty.

\section{METHODOLOGY}

Before discussing in detail the methodology applied to assess the competitiveness of Azerbaijani economy in contemporary international trade, it is worthwhile to first define the very concept of international trade competitiveness of an economy. Thus, according to the OECD definition (2005), it should be understood as the ability of an economy to compete fairly and effectively on the international markets for goods and services, which in turn leads to an improvement in the standard of living of its citizens in the long run. Additionally, Weresa (2014) stresses the dynamic character of this competitiveness, claiming that it is an ability to achieve faster (than other countries) and greater benefits from own and foreign factors of production in the conditions of an open economy. Falkowski (2017), on the other hand, defines the competitiveness of an economy in international trade as the ability of a given country, understood as the entire socio-economic system, to obtain specific competitive advantages in 
terms of international markets of production factors and markets of goods and services, as well as their permanent improvement in the conditions of a dynamically changing international environment.

In economic literature, there are a number of different methods and means of measuring international competitiveness in use. Among them, the index of Balassa and Lafay are relatively frequently used.

The values of the first index, i.e. Balassa's Revealed Comparative Advantage (RCA) index, were determined on the basis of the logarithmic original formula of B. Balassa $(1965,1989)$ according to the following formula:

$$
R C A_{i j}^{K}=\ln \left(\frac{\frac{x_{i j}^{K}}{X_{j}^{K}}}{\frac{x_{i}^{j}}{x^{j}}}\right)
$$

where:

$R C A_{i j}^{K}$ - the Revealed Comparative Advantages index of $K$ country for the $i$ goods category in relation to $j$ country or a group of $j$ countries;

$x_{i j}^{K}$ - exports of the $i$ goods category from $K$ country to $j$ country or a group of $j$ countries;

$X_{j}^{K}$ - total exports from $K$ country to $j$ country or a group of $j$ countries;

$x_{i}^{j}$ - exports of the $i$ goods category from $j$ country or a group of $j$ countries;

$X^{j}-$ total exports from $j$ country or a group of $j$ countries;

$i$ - goods category;

$K$ - analysed country;

$j$ - rest of the world.

By using the logarithmic form of the above formula, we obtain positive or negative values of the $R C A_{i j}^{K}$ index, which greatly facilitates their interpretation. We speak of the presence of a relative trade advantage for the $i$ goods category only when its share in total exports of a country is higher than the share of the $i$ goods category in total world exports, that is when the value of $R C A_{i j}^{K}>0$ (Falkowski, 2018).

In turn, the values of the latter indicator - the Lafay Index (LFI) of international trade specialization (Lafay, 1992), which is commonly used to assess the nature of a country's trade balance and, indirectly, its international competitiveness, were determined in accordance with the following formula:

$$
L F I_{i j}^{K}=100 \cdot\left(\frac{x_{i j}^{K}-m_{i j}^{K}}{x_{i j}^{K}+m_{i j}^{K}}-\frac{X_{j}^{K}-M_{j}^{K}}{X_{j}^{K}+M_{j}^{K}}\right) \cdot \frac{x_{i j}^{K}+m_{i j}^{K}}{X_{j}^{K}+M_{j}^{K}}
$$

where:

$L F I_{i j}^{K}$ - the Lafay Index of $K$ country for the $i$ goods category in relation to $j$ country or a group of $j$ countries;

$x_{i j}^{K}$ - exports of the $i$ goods category from $K$ country to $j$ country or a group of $j$ countries;

$X_{j}^{K}$ - total exports from $K$ country to $j$ country or a group of $j$ countries;

$m_{i j}^{K}$-imports of the $i$ goods category to $K$ country from $j$ country or a group of $j$ countries;

$M_{j}^{K}$ - total imports to $K$ country from $j$ country or a group of $j$ countries; 
$i$ - goods category;

$K$ - analysed country;

$j$ - rest of the world.

In this case, comparative advantages in foreign trade of a country exist when the values of the index for the $i$ goods category are positive $\left(L F I_{i j}^{K}>0\right)$, which means that the country has a trade surplus in that $i$ goods category.

Naturally, when applying both Balassa's Revealed Comparative Advantages (RCA) Index and the Lafay Index (LFI) of international trade specialization to the analysis of a country's level of competitiveness in international trade, one must be aware of their specific limitations and weaknesses.

And so, in the case of analysis using Balassa's Revealed Comparative Advantages (RCA) index, Siggel (2006) highlighted the fact that it was not possible to identify the sources of a country's potential comparative advantage in international trade using this method. What is more, he also pointed out the fact that the existence of these advantages does not have to be a sign of improvement of the general competitiveness and efficiency of a given economy, but that they might be due to e.g. a policy of state subsidies for production of specific goods or a policy of exchange rate manipulation. Similar conclusions were reached by Hinloopen and Van Marrewijk (2001), who claim that Balassa's method does not allow for exporter-sector (ex ante) specific factors to be isolated, i.e. the factors which are the source of comparative advantage. Furthermore, the way in which potential comparative advantages are assessed using Balassa's methodology is adversely affected by some weaknesses concerning empirical distribution, mostly time instability and poor ranking of ordinal property. Similar objections were raised by Costinot, Donaldson and Komunjer (2012), who state that, due to the simplicity of Balassa's method, subtleties such as heterogeneous preferences and heterogeneous trade costs are omitted, and therefore, using the RCA index, we show the effects and not the causes of existing comparative advantages. According to Laursen (2015) the major problem with the RCA index when applied across countries are large differences in country sizes. For instance, if exports of a certain product account for a large share of the country's total exports, but is only a very small fraction of total global exports, extremely high values will be achieved. Deb and Hauk (2017) emphasize that as the importance of global production chains is growing, RCA indices - which are based on gross export values - may not give an accurate portrayal of the underlying comparative advantage enjoyed by countries. Therefore, they should be adjusted to incorporate domestic value-added in exports. According to Gnidchenko and Salnikov (2015), three main weaknesses of the original formula of Balassa's RCA index can be identified, namely: 1) its sensitivity to the number of exported goods and countries researched;2) its values for one good are dependent on its values for other goods, as a higher share of one good in total exports means a lower share of other goods in them; 3) its asymmetry, significantly limiting the possibility to compare its values over time and space.

Due to the weaknesses and limitations of Balassa's methodology indicated above, in the literature on the subject there have been attempts to construct standardised indicators of relative comparative advantage, e.g. the additive RCA (Hoen \& Oosterhaven, 2006), the standardized index of relative comparative advantage (Yu, Cai \& Leung, 2009), and the relative symmetrical comparative advantage index (Dalum, Laursen \& Villumsen, 1998; Iapadre, 2001). It should be noted, however, that so far they have not been widely recognised by economists dealing with the international competitiveness of economies.

Nevertheless, despite these weaknesses, Balassa's RCA index remains one of the most widely used means of measuring international trade specialisation and comparative advantages in trade. This is due to its greatest advantage, which is the simplicity of the construction of the index itself, as well as the 
interpretation of the results obtained (Gnidchenko \& Salnikov, 2015). Moreover, it also provides an opportunity to assess changes in comparative advantages in relation to goods with a specific, different absorption capacity of input factors used in their production (e.g. technologically advanced goods) in the long run.

As for the limitations and weaknesses of Lafay's Index (LFI) of international trade specialization, like Balassa's RCA index, it does not identify the potential reasons for the presence, or lack, of comparative advantages in a country's international trade. Additionally, as LFI is a relative measure, caution is asked for when interpreting the results and one should be aware of their limitations (Gnidchenko \& Salnikov, 2015).

What is more, the essence of this index (interpretation of its results) boils down to verifying the existence of surplus or deficit in trade turnover of a given category of goods on the international market. Therefore, a simplified assumption is made that a surplus in trade with foreign countries in a given product category indicates that this product category is internationally competitive in trade, while a deficit indicates a lack of such competitiveness.

Moreover, Gnidchenko and Salnikov (2015) also stress that the values of the index depend mostly on the relative share of a given product in the country's trade turnover (that is, its values suffer from the scale effect). This problem is serious, as due to classification issues goods are not equal in trade volumes.

Another serious limitation and weakness of this indicator, as pointed out by Sanidas and Shin (2010), is that LFI does not take account of global variables, unlike Balassa's RCA index. This makes it very difficult to compare the results obtained in this way for a given country with the results obtained for other countries, due to a specific lack of a common reference point, which is ensured by Balassa's index.

However, despite its weaknesses, LFI is the second most widely used indicator for assessing a country's international trade competitiveness, next to Balassa's RCA index. Its specific merit and advantage over Balassa's index is that by including imports, it helps keep in check intra-industry trade and re-export flows; in this sense it is better that the traditional Balassa's RCA index (Zaghini, 2003).

In order to conduct a detailed analysis of the subject-matter of this article, the OECD classification of goods categories based on their technological advancement was applied. In line with this classification, 4 basic categories of goods are distinguished, i.e. high, medium-high, medium-low and low technology goods (OECD, 2011; Hatzichronoglou, 1997).

All the necessary annual data (for individual years included in the analysis) used to analyse the issue of competitiveness were derived from the United Nations Commodity Trade Statistics Database.

\section{EMPIRICAL RESEARCH RESULTS}

When conducting a detailed analysis of Azerbaijani exports in 2000-2015, using the methodology discussed earlier, it should be emphasized that the overall competitiveness of the Azerbaijani economy on the international arena is relatively low. This is most clearly evidenced by the fact that in the analysed period Azerbaijan did not have any revealed comparative advantages in the trade of goods from high, medium-high and even low technology groups in general (Figure 1). Azerbaijan's only comparative

advantage during the period in question (albeit also periodically, in fact only until 2007) was in the category of medium-low technology goods in general. It is worth mentioning at this point that 2008 was a particularly unfavourable year for the Azerbaijani economy, which was also reflected in the overall competitive profile of the country. The global financial crisis and, with it, the fall in the prices of energy resources, especially crude oil and its derivatives, had a very negative impact on the macroeconomic situation in Azerbaijan, as well as on its exports, both in terms of value and commodity structure.

The main reason for the loss of comparative advantages in the category of medium-low technology goods in general starting from 2007 was, in fact, a significant (or even dramatic) decline in the 
competitiveness of the Azerbaijani economy in the area of ship and boat production, as well as, to a lesser extent, in the area of trade in rubber and plastic products, which belong to the category of medium-low technology goods, even though at the same time Azerbaijan's competitiveness in trade in mineral fuels, oils and products of their distillation did not decrease, but even increased.

Taking into account the RCA values in the analysed period, Azerbaijan fared by far the worst in terms of international competitiveness in trade in the category of high and medium-high technology goods in general, which should be assessed as absolutely negative, especially in the modern world economy, where due to changes in the structure of global demand, the significance of goods coming from industries that use modern factors of production and are characterized by a high level of innovation is growing.

In turn, if we look at the value of the LFI index in 2000-2015, it turns out that Azerbaijan recorded a very high negative trade balance in the medium-high technology goods category throughout the analysed period. The worse result in this category as compared to the category of high technology goods was a direct consequence of a much higher value of the amplitude between exports and imports of Azerbaijan in this category.

(Balassa's) RCA index

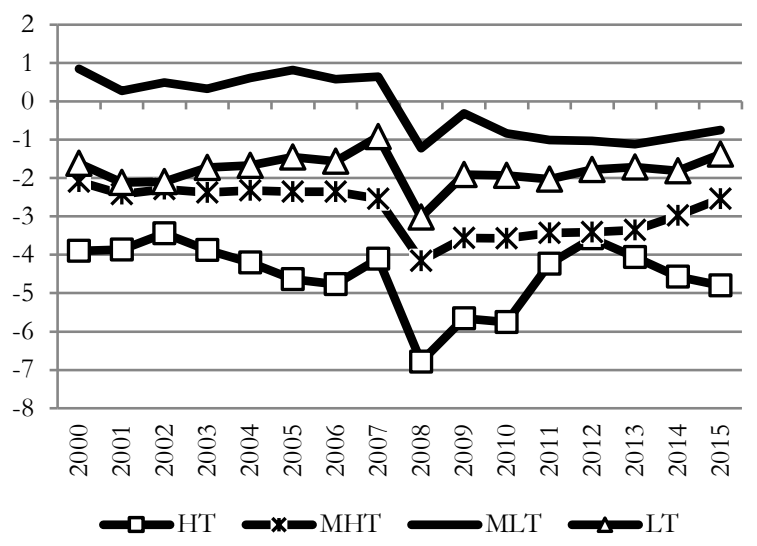

(Lafay's) LFI index

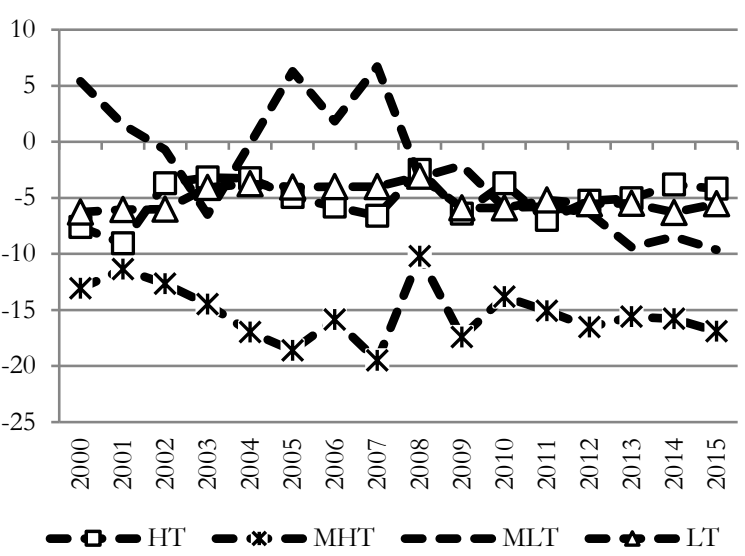

Figure 1. Azerbaijan's revealed comparative advantages in trade of high, medium-high, medium-low and low technology goods in the years 2000-2015

HT - high technology goods, MHT - medium-high technology goods, MLT - medium-low technology goods, LT - low technology goods Source: Own study based on United Nations Commodity Trade Statistics Database.

In the following part of the article, a detailed analysis of Azerbaijan's international trade competitiveness in each of the four categories of goods, according to the OECD classification of goods based on their technological advancement, was conducted.

In the case of the high-technology category of goods, Azerbaijan did not enjoy any comparative advantages in the years 2000-2015 in the export of individual goods belonging to this goods category (all values of the RCA < 0 ) (Figure 2). In practice, this meant that the share of high-technology goods in Azerbaijan's total exports to the international market was lower than the share of these goods in global exports. What is more, also for each subcategory of goods in this category, Azerbaijan did not record a surplus in foreign trade (positive trade balance) (all values of LFI $<0$ ) during the analysed period, which additionally confirms the uncompetitive nature of the Azerbaijani economy with respect to this category on the international arena. There is no doubt that the still low level of innovation in the Azerbaijani economy, as well as its resources-based nature, explains the situation in this area. 
(Balassa's) RCA index

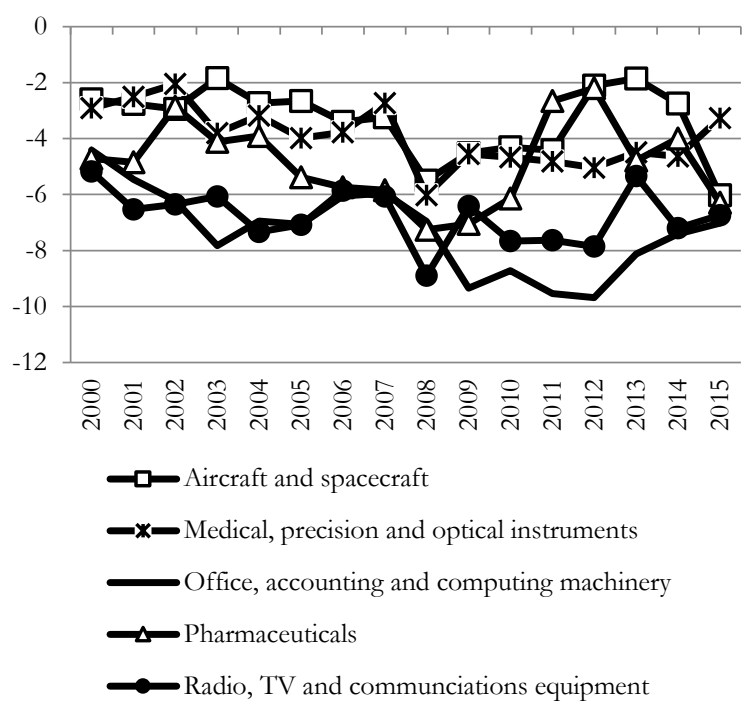

(Lafay's) LFI index

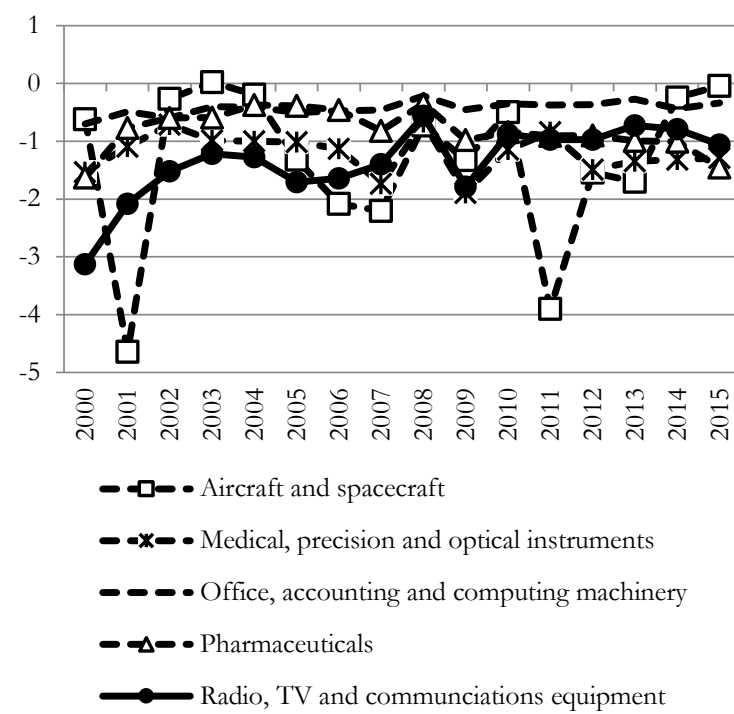

Figure 2. Azerbaijan's revealed comparative advantages in the trade of high technology goods in the years 2000-2015

Source: Own study based on United Nations Commodity Trade Statistics Database.

Azerbaijan is by far the most internationally uncompetitive in the following subcategories: Office, accounting and computing machinery and Radio, TV and communications equipment (by far the lowest values of the RCA index over the entire analysed period).

Next, if we look at the dynamics of the RCA index in Azerbaijan's exports in relation to the individual subcategories of goods from the medium-high technology goods category according to the OECD classification over the years 2000-2015, it turns out that, similarly to the previously analysed subcategories of goods from the high technology goods category, in this case also no comparative advantages were recorded in these subcategories (all values of the RCA index $<0$ ).

The most internationally uncompetitive Azerbaijani goods with a medium-high level of technological advancement were from the Motor vehicles, trailers and semi-trailers subcategory (Figure 3). Throughout the entire analysed period, Azerbaijan also recorded a very high negative trade balance in terms of trade in this particular goods subcategory, which further confirms the fact that it is not competitive on the international arena as mentioned above, as well as that domestic production cannot meet the demand for these goods. It is worth noting that Azerbaijan recorded an even higher negative trade balance in the subcategory of Machinery and equipment, n.e.c. (the lowest LFI values in the whole category of mediumhigh technology goods).

Azerbaijan is also not internationally competitive in trade in medium-low technology goods, albeit with one very important exception (Figure 4). In terms of trade in the subcategory of Coke, refined petroleum products and nuclear fuel, Azerbaijan possessed revealed comparative advantages (values of the RCA index $>0$, which meant that the share of these goods in Azerbaijani exports to the international market was higher than the share of these goods in total global exports) in the entire analysed period between 2000-2015. This proved the real international trade competitiveness of its economy in this subcategory. What is more, Azerbaijan also recorded a positive trade balance in this subcategory of goods (LFI values > 0). It is worth noting, however, that both in the case of the RCA and LFI indices, over the analysed period 2000-2015 a significant decrease for this subcategory of goods can be observed 
(particularly visible in the case of the LFI values). This should be clearly assessed negatively from the point of view of the Azerbaijani economy's competitiveness in respect to these goods in the long term as it means that Azerbaijan is gradually losing its comparative advantages in international trade.

(Balassa's) RCA index

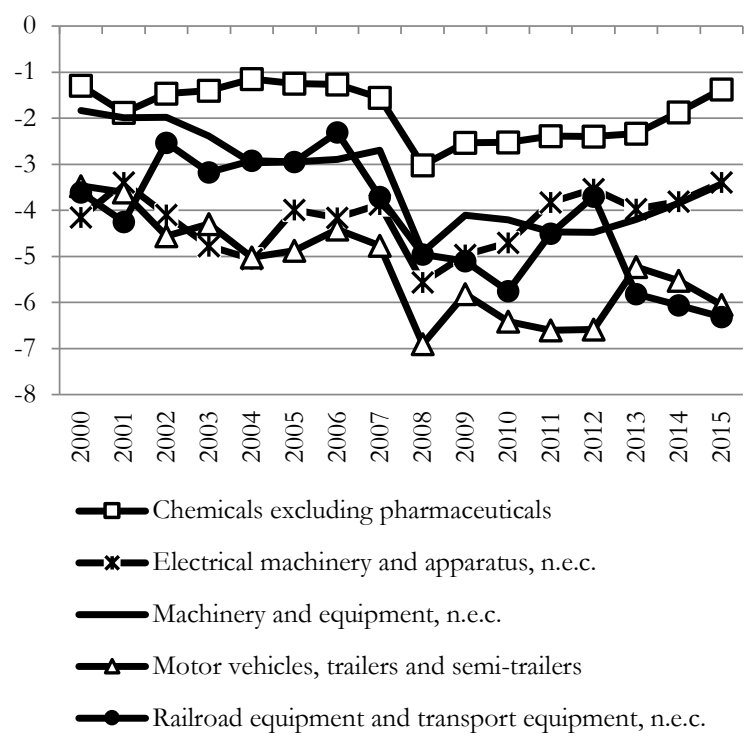

(Lafay's) LFI index

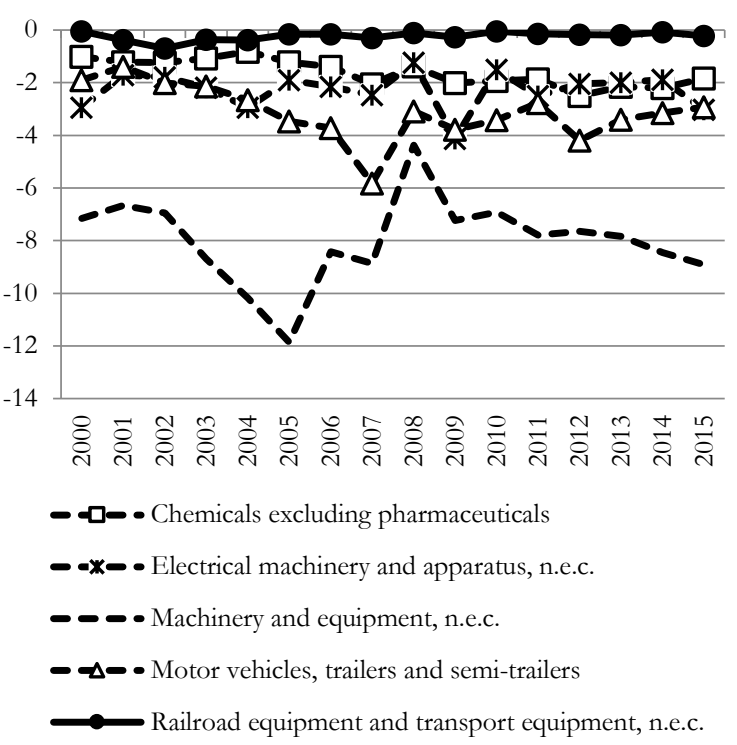

Figure 3. Azerbaijan's revealed comparative advantages in the trade of medium-high technology goods in the years 2000-2015

Source: Own study based on United Nations Commodity Trade Statistics Database.

(Balassa's) RCA index

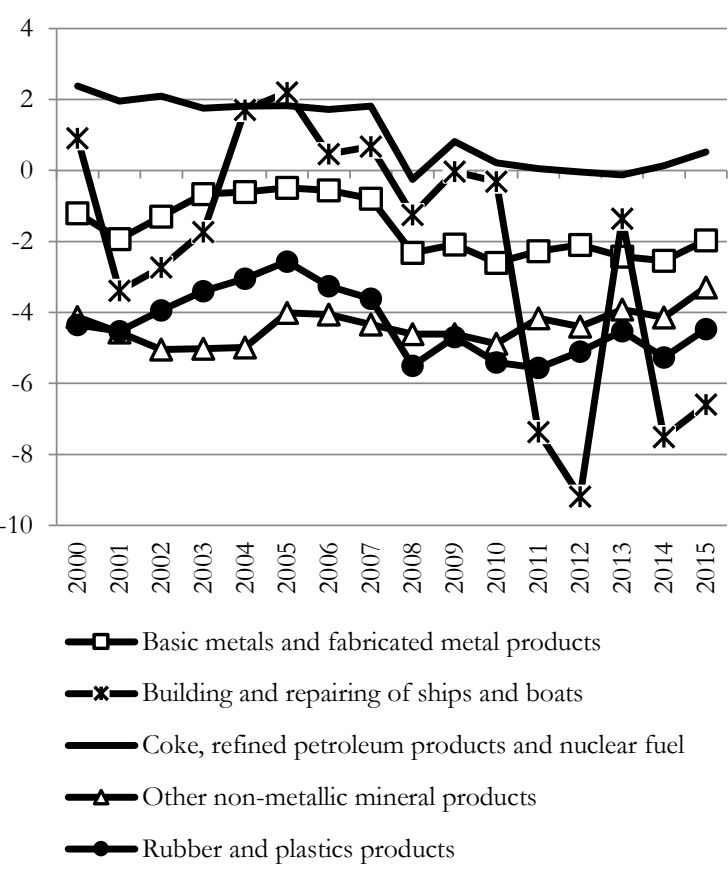

(Lafay's) LFI index

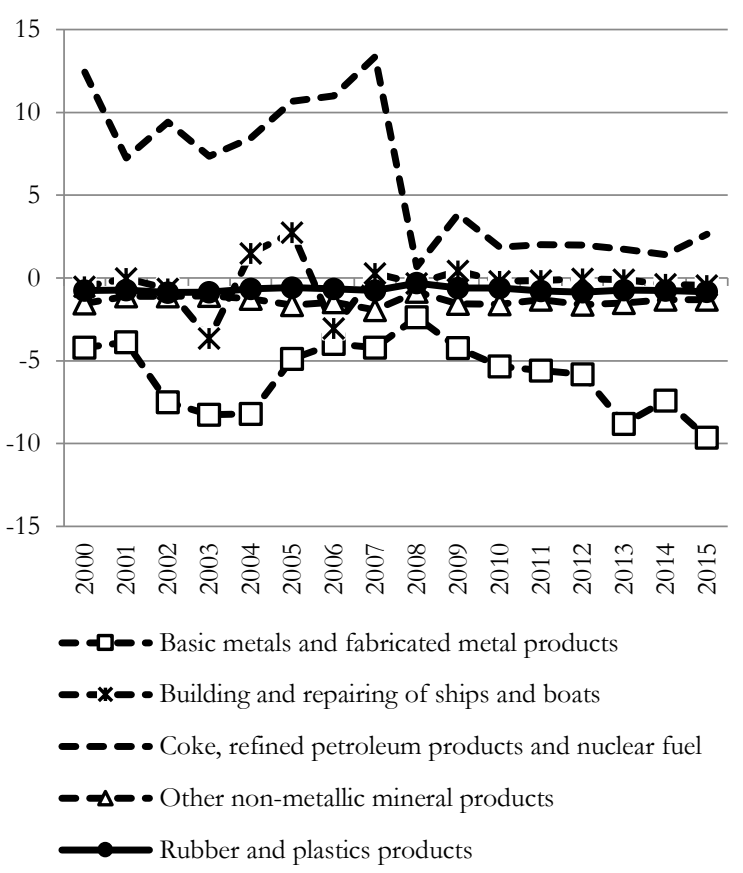

Figure 4. Azerbaijan's revealed comparative advantages in the trade of medium-low technology goods in the years 2000-2015

Source: Own study based on United Nations Commodity Trade Statistics Database. 
Still remaining in the medium-low technology goods category, it is worth examining the development of potential comparative advantages in Azerbaijan's exports with respect to a slightly different group of goods than defined in the OECD classification, namely one containing mineral fuels, oils and products of their distillation. As for Azerbaijan's international trade competitiveness, it is evident that the country is very competitive in this group (Figure 5). Moreover, LFI values for trade in these goods are very high, which indicates Azerbaijan's very high positive trade balance in respect to this group of goods. Moreover, in this case, over the whole period under consideration this competitiveness, despite some minor fluctuations, remained stable. This is particularly important from the point of view of the macroeconomic conditions in which the entire economy operates, as well as the Azerbaijani state in general, where the majority of state revenues comes from the export of mineral fuels and their derivatives.

Of course, we should be aware that such high, relatively stable competitiveness of Azerbaijan in this area results from its large base of these natural resources and their exploitation, and from the fact that the country exports them in the presence of a large demand for them on the international arena. Therefore, unfortunately, it is not a consequence of its economy's modernisation, improvement of its innovativeness or change in its structure towards e.g. a knowledge-based economy.

(Balassa’s) RCA index

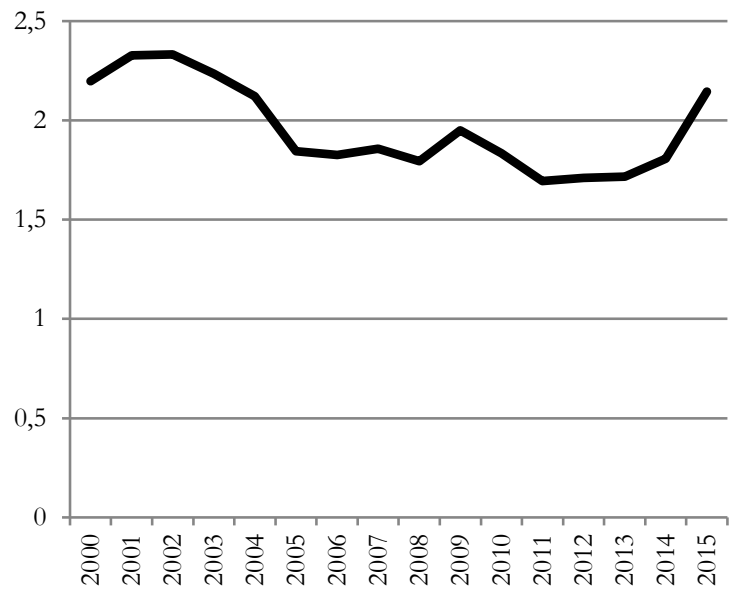

(Lafay's) LFI index

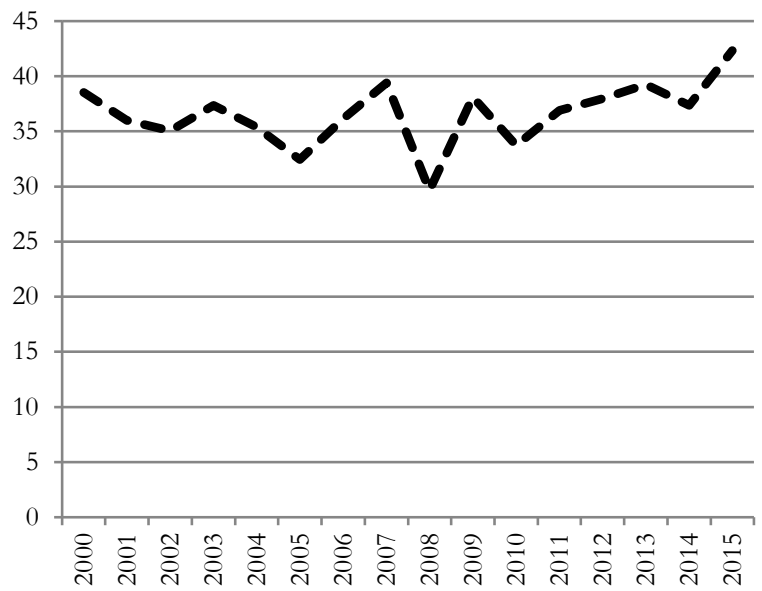

Figure 5. Azerbaijan's revealed comparative advantages in trade of mineral fuels, oils and products of their distillation in the years 2000-2015

Source: Own study based on United Nations Commodity Trade Statistics Database.

Then, when analysing Azerbaijan's international trade competitiveness in individual subcategories of goods from the last, fourth category of goods, as defines in the OECD classification, i.e. in low technology goods, once again it should be stressed that the country did not possess any revealed comparative advantages in any of them (Figure 6). In practice, this meant that the share of these low technology goods in Azerbaijan's total exports to the international market was lower than the share of these goods in global exports. The results obtained are consistent with, among others, the conclusions of the research conducted by Almas and Hajiyev (2014). 
(Balassa's) RCA index

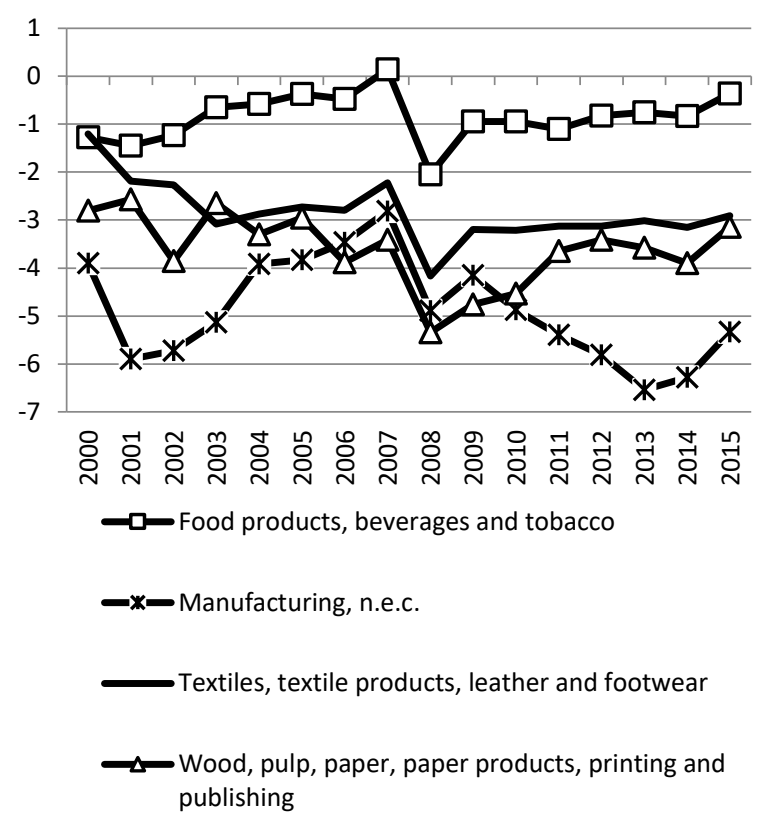

(Lafay's) LFI index

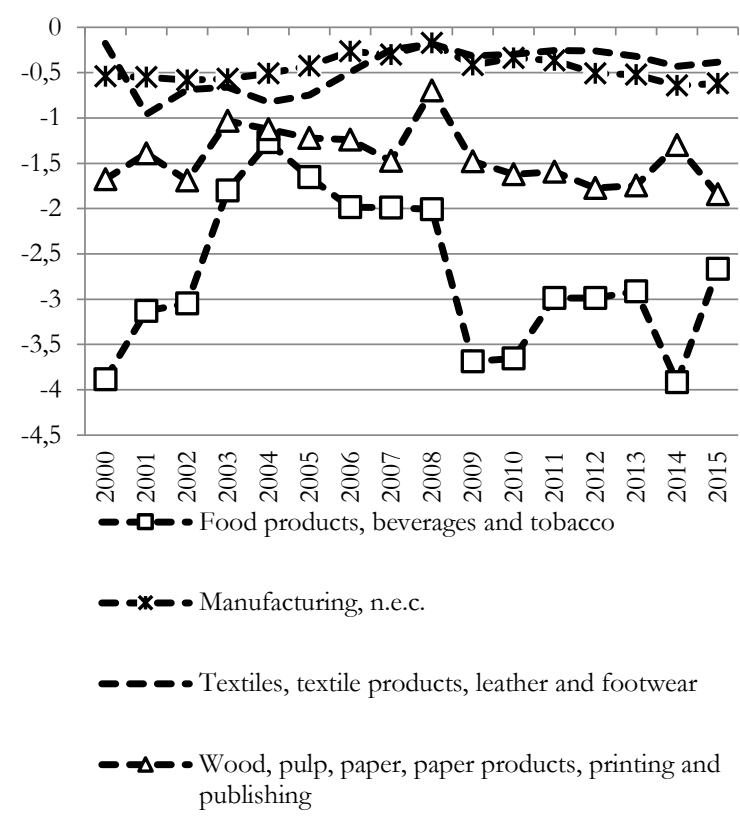

Figure 6. Azerbaijan's revealed comparative advantages in the trade of low technology goods in the years 2000-2015

Source: Own study based on United Nations Commodity Trade Statistics Database.

Only once during the entire analysed period 2000-2015, Azerbaijan recorded small comparative advantages in trade in the Food, beverages and tobacco subcategory (in 2007, value of the RCA index $=$ 0.14). It should also be stressed that despite the fact that negative values of RCA indices for this subcategory of goods were relatively lowest as compared to the other subcategories of low technology goods, Azerbaijan recorded a very strong negative trade balance in this subcategory throughout the analysed period (as evidenced by the lowest values of LFI). This is due to the structure and specific nature of Azerbaijani agriculture, which is unable to meet the existing domestic demand for this range of consumer goods.

\section{CONCLUSIONS}

The analysis of the dynamics of revealed comparative advantages in Azerbaijan's exports in the years 2000-2015 has clearly shown that that the overall competitiveness of the Azerbaijani economy in international trade is low and that, moreover, it has not significantly improved over the analysed period. And that the possessed and exploited energy resources and their derivatives are absolutely crucial from the point of view of the Azerbaijani economy's international trade competitiveness. In fact, it is only in the area of exports of mineral fuels, as well as oils and products of their distillation that Azerbaijan has had a relatively stable, strong comparative advantage over the years. It is a very important determinant of the macroeconomic conditions in which the Azerbaijani economy operates.

Taking into account the objective limitations of the research methods applied, in this article no reasons have been identified for the actual low competitiveness of the Azerbaijani economy. Due to the specific simplicity of the research methods, the analysis omitted such subtleties as heterogeneous preferences and heterogeneous trade costs, and therefore, the effects, and not causes, of the existing comparative advantages were shown. In addition, the impact of possessed and exploited natural resources 
and their derivatives on the competitiveness of the entire Azerbaijani economy was not determined either. In this case, an appropriate econometric model should be developed, or at least the Bayesian linear regression method should be applied, which would enable such a detailed analysis to be made in this respect. It would also be very interesting to take a look at the analysis of the competitiveness of the Azerbaijani economy from the sectoral approach.

Clearly, from the point of view of further in-depth research into the competitiveness of the Azerbaijani economy, which seems to be very desirable, e.g. due to the fact that the country is looking for ways to maintain the dynamic growth rate of its economy in the future, as well as research into the competitiveness of raw material economies themselves, it seems that undertaking such targeted research seems to be all the more advisable and desirable. This is all the more justified as English-speaking international literature clearly lacks such studies.

\section{REFERENCES}

Aliyev, S. (2014). Economics of Azerbaijan: upgrading and implementation of effective instruments. Life Science Journal, 11, 321-326.

Almas, L.K., \& Hajiyev, N.U. (2014). Azerbaijan's Current and Potential Comparative Advantage: An Exploratory Study. Journal of Agricultural Science, 6(11), 74-87. doi: 10.5539/jas.v6n11p74

Azerbaijan 2020: Look into the Future (2013). Retrieved from http://www.president.az/files/future_en.pdf (22.03.2018).

Bahmani-Oskooee, M., \& Jamilov, R. (2014). Export diversification and the S-curve effect in a resource-rich state: evidence from Azerbaijan. Economic Change and Restructuring, 47(2), 135-154. doi: 10.1007/s10644-013-9145-8

Balassa, B. (1989). 'Revealed' comparative advantage revisited. In: B. Balassa, Comparative advantage, trade policy and economic development, New York: New York University Press.

Balassa, B. (1965). Trade liberalization and 'revealed' comparative advantage. The Manchester School of Economic and Social Studies, 33(2), 99-123.

Bayramov, V. (2014). Competitiveness in Azerbaijan. Assessing Sectorial Economic Policies, Friedrich-Ebert-Stiftung, Baku: Center for Economic \& Social Development.

Costinot, A., Donaldson, D., \& Komunjer, I. (2012). What Goods Do Countries Trade? A Quantitative Exploration of Ricardo's Ideas. Review of Economics Studies, 79, 581-608. doi: $10.1093 / \mathrm{restud} / \mathrm{rdr} 033$

Dalum, B., Laursen, K., \& Villumsen, G. (1998). Structural Change in OECD Export Specialization Patterns: despecialization and 'stickiness'. International Review of Applied Economics, 12(3), 423-443. doi: 10.1080/02692179800000017

Deb, K., \& Hauk, W.R. (2017). RCA indices, multinational production and the Ricardian trade model. International Economics and Economic Policy, 14(1), 1-25. doi: 10.1007/s10368-015-0317-z

Falkowski, K. (2018). Competitiveness of the Baltic States in International High-Technology Goods Trade. Comparative Economic Research, 21(1), 25-43. doi: 10.2478/cer-2018-0002

Falkowski, K. (2017). Long-Term Comparative Advantages of the Eurasian Economic Union Member States in International Trade. International Journal of Management and Economics, 53(4), 27-49. doi: 10.1515/ijme-2017-0024

Gnidchenko, A.A., \& Salnikov, V.A. (2015). Net Comparative Advantage Index: Overcoming the Drawbacks of the Existing Indices. Higher School of Economics Research Paper, No. WP BRP 119/EC/2015. doi: $10.2139 / \operatorname{ssrn} .2709009$

Hasanov, F. (2013). Dutch disease and the Azerbaijan economy. Communist and Post-Communist Studies, 46(4), 463-480. doi: 10.1016/j.postcomstud.2013.09.001

Hatzichronoglou, T. (1997). Revision of the high technology sector and product classification. STI Working Papers 1997/2. OECD/GD 97(216). Paris: Organisation for Economic Co-operation and Development.

Hinloopen, J. \& Van Marrewijk, C. (2001). On the empirical distribution of the Balassa Index. Weltwirtschaftliches Archiv, 137, 1-35. doi: 10.1007/BF02707598

Hoen, A.R., \& Oosterhaven, J. (2006). On the measurement of comparative advantage. The Annals of Regional Science, 40(3), 677-691. doi: 10.1007/s00168-006-0076-4

Iapadre, P.L. (2001). Measuring international specialization, International Advances in Economic Research, 7(2), 173-183. doi: $10.1007 / \mathrm{BF} 02296007$

Ibragimova, S., \& Isayev, N. (2017). Development of the Non-Performing Sector of Independent Azerbaijan, SSRN Electronic Journal, Retrieved from https://ssrn.com/abstract=2960151 (11.02.2018). 
Lafay, G. (1992). The Measurement of Revealed Comparative Advantages. In: M.G. Dagenais/P.A. Muet, International Trade Modeling. London: Chapman \& Hill.

Laursen, K. (2015). Revealed comparative advantage and the alternatives as measures of international specialization. Eurasian Business Review, 5(1), 99-115. doi: 10.1007/s40821-015-0017-1

Mukhtarov, E. (2018). The Economy of Azerbaijan in 2017 - Brief Overview, Baku: Center for Economic and Social Development.

Musayev, V. (2016). Challenges for Sustainable Economic Development: Evidence from Azerbaijan, CAERC Working Paper, Baku: Center for Analysis of Economic Reforms and Communication.

OECD (2011). ISIC Rev. 3 Technology intensity definition. Classification of manufacturing industries into categories based on R $D^{D}$ intensities. Retrieved from http://www.oecd.org/sti/ind/48350231.pdf (13.03.2018).

OECD (2005). OECD Glossary of Statistical Terms, Retrieved from http://stats.oecd.org/glossary/detail.asp?ID=399 (02.03.2018).

Pashayev, F. (2013). Investment policies and competitiveness of Azerbaijani economy. Khazar Journal of Humanities and Social Sciences, 16(2), 22-31. doi: 10.5782/2223-2621.2013.16.2.22

Sanidas, E., \& Shin, Y. (2010). Comparison of Revealed Comparative Advantage Indices with Application to Trade Tendencies of East Asian Countries, Seoul: Seoul National University.

Siggel, E. (2006). International Competitiveness and Comparative Advantage: A Survey and a Proposal for Measurement. Journal of Industry, Competitiveness and Trade, 6(2), 137-159. doi: 10.1007/s10842-006-8430-x

Weresa, M.A. (2014). Innovation, Human Capital and Trade Competitiveness. How Are They Connected and Why Do They Matter?, Switzerland: Springer International Publishing.

World Bank Database (2018). Retrieved from https://data.worldbank.org/ (12.04.2018).

Yu, R., Cai, J., \& Leung, P. (2009). The normalized revealed comparative advantage index, The Annals of Regional Science, 43(1), 267-282. doi: 10.1007/s00168-008-0213-3

Zaghini, A. (2003). Trade Advantages and Specialisation Dynamics in Acceding Countries, Working Paper Series No 249, Frankfurt am Main: European Central Bank.

Zeynalov, F. (2016). The Oil and Gas Resources of Azerbaijan. A country's transformation into a regional energy bub, SaintDenis: Connaissances et Savoirs. 